\title{
An economic analysis of the EHAS telemedicine system in Alto Amazonas
}

\author{
Andrés Martínez*, Valentín Villarroel ${ }^{\dagger}$, Jaume Puig-Junoy \\ Joaquín Seoane ${ }^{\S}$ and Francisco del Pozo ${ }^{\dagger}$
}

*Departamento de Teoría de la Señal y Comunicaciones, Universidad Rey Juan Carlos, Madrid; ${ }^{\dagger}$ Grupo de Bioingeniería y Telemedicina de la Universidad Politécnica, Madrid; 'Departamento de Economía y Empresa de la Universitat Pompeu Fabra, Barcelona; ${ }^{\circledR}$ Departamento de Ingeniería Telemática de la Universidad Politécnica, Madrid, Spain

\begin{abstract}
Summary
Telemedicine systems providing voice communication and email by radio were installed at seven health centres (HCs) and 32 health posts (HPs) in the Alto Amazonas province of Peru during 2001. A cost analysis was performed to estimate the net effect on direct resource consumption from the perspective of society. Prior to the availability of the EHAS telemedicine system, there was a mean of 11.1 urgent patient referrals per year from the HPs and 14.0 referrals per year from the HCs. After the implementation of telemedicine, patient referrals fell to 2.5 per year from the HPs $(P=0.03)$ and to 8.4 per year from the HCs $(P=0.17)$. The net economic effect of the telemedicine programme over a four-year period was clearly positive, amounting to annual net savings of US\$320,126 (using a $5 \%$ discounting rate). A one-way sensitivity analysis using a range of values for the discounting rate, and the number of urgent referrals, confirms that the programme was efficient (i.e. it made net financial savings) in all cases. From the restricted budgetary perspective of the health network, the results also demonstrate that the additional operational costs (telephone and maintenance) introduced by the telemedicine system were lower than the direct cost-savings produced for the health-care network.
\end{abstract}

\section{Introduction}

There has been relatively little use of Information and Communication Technologies (ICTs) in rural health in developing countries. The first problem is economic sustainability. We have investigated the economic sustainability of a pilot project named 'EHAS-Alto Amazonas' (Hispanic American Health link - Alto Amazonas). The project uses ICTs for rural health care in a very isolated area in the Peruvian jungle. A range of information services are provided, including distance learning, information exchange and distance consultation.

The EHAS programme (http://www.ehas.org) began in 1997 studying the use of ICTs to improve the work condition of health-care personnel in rural areas of

Accepted 18 May 2006

Correspondence: Andrés Martínez, Departamento de Teoría de la Señal y Comunicaciones, Despacho B-103, Campus de Fuenlabrada, Universidad Rey Juan Carlos, Camino del Molino s/n. 28943 Fuenlabrada, Spain (Fax: +3491488 7500; Email: andres.martinez@urjc.es) developing countries. There are five areas of work: (1) analysis of information and communication needs of health staff; (2) development of telecommunication systems for voice and data communication using low-cost wireless technologies; (3) development of information systems for distance learning, computerization of an epidemiological surveillance system, teleconsultation, emergency management and drug distribution; (4) demonstration projects and (5) impact and sustainability evaluation of the demonstration projects.

EHAS has developed a methodology and several tools for the assessment of the information and communication needs of rural health-care staff. ${ }^{1}$ This methodology has been used for studies in Peru, Nicaragua, Colombia and Mexico. In places where there is no access to the public telephone network, telecommunication for voice and email are based on radio systems such as VHF, HF or WiFi. ${ }^{2}$ The alternative to electronic transmission is either postal or courier services. However, in Alto Amazonas, postal services exist only in the capital of the province (Yurimaguas). 
The EHAS programme has developed pilot projects in Peru, Colombia and Cuba (in the rain forest and mountain regions). The results of these projects are deployment of telecommunication infrastructure, distance learning for health-care staff and computerization of epidemiological surveillance. ${ }^{3}$ The projects have included the work with local health-care authorities to redesign the processes of patient transfer and drug distribution.

A recent article published in this journal ${ }^{4}$ evaluated the first pilot project. The pilot project was developed in the Alto Amazonas province and involved seven health centres (HCs) and 32 health posts (HPs). This study assessed whether the EHAS telemedicine system was associated with lower direct health and nonhealth-care costs, than the previous conventional situation (i.e. a before and after comparison).

The main objective of the present study was to perform a cost analysis of the net effect of the EHAS programme on direct resource consumption from the perspective of society in a four-year period.

\section{Methods}

The cost analysis was designed to measure the additional costs incurred and avoided costs that were associated with the EHAS programme (i.e. the net cost). That is, the cost analysis compared before and after scenarios resulting from the EHAS programme, and it also assessed changes in direct health and non-healthcare programme-related costs.

The societal perspective was adopted in the cost analysis. Monetary values were calculated using 2002 US\$, that is, they were valued at the first year of the programme implementation. Both additional and avoided resources in the after period associated with the EHAS programme were discounted at 3 and 5\% rates, as is common in the economic evaluation literature. The ICT equipment used in the programme is expected to be in use for at least a four-year period before renewal. So the time horizon employed in the cost analysis was four years after programme implementation.

Information on resource consumption in the period before the EHAS programme began was obtained from a baseline case study carried out in January 2001. Information on resource consumption resulting from the implementation of the EHAS programme was recorded in May 2002, after 12 months of operation of the EHAS network. Data for the before and the after intervention scenarios were obtained through structured interviews with the professionals in charge of 32 of the 39 establishments affected by the programme.

Seven categories of resource consumption were identified:

(1) fixed capital investment in the equipment (power supply, communication, radio transmission and workstation);

(2) variable resources associated with the EHAS equipment (maintenance and repair, telephone, consumables, computer training for new employees and personnel developing the distancelearning courses);

(3) changes in resources used by the health-care personnel in the trips to their referral centre (RC) either to the head of the district (HD) or to the provincial hospital of Yurimaguas (PHY). Resources in this category included transportation, accommodation and per diems. These trips were for several purposes: coordination of activities, attending training courses, delivery of epidemiological surveillance reports and other related reports, consultations and drug distribution;

(4) changes in travel and accommodation expenses related to urgent patient referrals;

(5) changes in resources associated with differences in traditional training courses;

(6) changes in the time of the health-care personnel devoted to travelling to their RC and the time devoted to completing reports;

(7) changes in the time of patients and their relatives (companion) devoted to urgent referrals to the hospital.

The EHAS equipment was valued using observed purchase prices. Variable resources related to the EHAS equipment use were valued using average prices declared by health-care personnel in May 2002. The cost of trips by health-care personnel to their RC were based on the average number of trips to the HD and to the PHY from HPs and HCs in January 2001 and May 2002, the average number of nights stayed out in each trip and average observed prices in January 2001 for transportation, per diem allowances and daily accommodation. The cost of urgent patient referrals to the hospital were based on the average number of urgent referrals from HPs and from HCs in January 2001 and May 2002, and the average observed cost of transportation, per diem, daily accommodation and hospital care. Changes in resources devoted to traditional training courses were valued by considering the number of courses for each health establishment and the daily cost of the teacher (the cost of trips for transportation, per diem and accommodation). 
Changes in the time of the health-care personnel devoted to travelling to their $\mathrm{RC}$ were valued by considering the average observed difference before and after EHAS implementation in the number and duration of the trips, and the average daily salary of technicians and doctors. Changes in the time of the health-care personnel devoted to completing reports were valued according to the estimated hours saved and their average salary. Changes in the time of patients and their relatives (companion) devoted to urgent referrals to the hospital were valued by considering the average observed difference before and after EHAS implementation in the number of referrals, two persons involved in the trip (the patient and a companion), the average number of lost days and the average salary. In this last case, it was the value of the avoided time devoted to obtaining health care that was measured and not the value of any health improvement.

The analysis presented in this paper was limited to the effect of the EHAS programme on resource consumption (cost impact analysis), with the implicit, but unproven, hypothesis that these changes in the use of resources resulting from programme intervention had no negative effect on health outcomes.

In order to assess the effect of uncertainty in the results of this cost analysis, a one-way sensitivity analysis was performed using alternative values for the discounting rate and the number of urgent referrals to the hospital from each health establishment.

\section{Results}

\section{Fixed capital and variable costs of the telemedicine systems}

A total of 39 wireless systems were installed for voice and data communication in the EHAS project. The average fixed capital cost was $\$ 4195$ per system (20\% was added towards installation costs), Table 1.
The variable costs of the EHAS equipment at each establishment were based on the following: (1) the maintenance and repair costs, (2) the telephone bill for the email servers, (3) consumables (distilled water for the batteries, paper and printer ribbons), (4) the computer-training costs of the new personnel and (5) the personnel in charge of developing the distant training courses.

To assess the repair costs during the first year of operation, we took into account the number of failures of the voice system (a mean of 0.31 per establishment per year), and of the email system (a mean of 1.26 per establishment per year). In order to repair failures, an average of 1.57 trips a year to each establishment was required. The average cost of fuel to travel to an establishment was \$30. The average cost of the per diem allowance was $\$ 20$ during 2 days. A one-night stay in a hostel was also required for each system failure. Finally, taking into account that one out of three system failures required the replacement of electronic parts, with a mean cost of $\$ 100$, the total annual cost of repairs was $\$ 140.43$ per establishment.

Five HCs with telephone lines, where the radiotelephone gateways were installed, paid a flat rate of \$50 per month that allowed 200 local telephone calls and $45 \mathrm{~h}$ of Internet access. Other centres without the flat rate contract estimated that the system increased their previous bill by $\$ 25$ per month. Thus, the average additional annual telephone costs were $\$ 84.62$ per establishment.

Each health site supported the following operational expenses: (1) \$0.86 monthly for paper (HPs and HCs consumed an average of 86 and 470 sheets of paper), (2) one printer ribbon each year (\$7.00) and (3) \$7.80 yearly for battery distilled water. Thus, the average annual consumables cost was $\$ 25.12$ per establishment.

In addition, the costs of informatics training for new employees and the costs of personnel developing the distance learning courses were an average of $\$ 84.33$ per establishment per year.

Table 1 Fixed costs of a single telemedicine system

\begin{tabular}{|c|c|c|}
\hline Resource & Accessories & Cost $(\$)$ \\
\hline Energy supply & $\begin{array}{l}\text { Two solar panels of } 75 \mathrm{~W} \text {, one battery of } 225 \mathrm{Ah} \text {, one photovoltaic } \\
\text { regulator of } 30 \mathrm{~A} \text {, one inverter of } 75 \mathrm{~W} \text {, two lights of } 13 \mathrm{~W} \text {, panel } \\
\text { support, box of batteries and accessories }\end{array}$ & 1450 \\
\hline Communication & One VHF transceiver, one radio modem, box and accessories & 685 \\
\hline Transmitter & $\begin{array}{l}\text { One tower of } 15 \mathrm{~m} \text { with accessories, one VHF antenna, civil works, one } \\
\text { lightning conductor, coaxial cable and accessories }\end{array}$ & 800 \\
\hline Workstation & One laptop, one printer, one PC & 1260 \\
\hline Total equipment & & 4195 \\
\hline Installation costs (20\%) & & 839 \\
\hline Grand total & & 5034 \\
\hline
\end{tabular}


The total monthly variable cost related to the telemedicine system in the 39 health establishments of the EHAS programme was $\$ 1087.11$, Table 2. Thus, the average variable cost of the EHAS telemedicine system for each establishment was $\$ 334.5$ per year.

\section{Changes in the costs of health-care personnel trips}

The health personnel of a HP made an average of 4.4 trips per quarter to the $\mathrm{HD}$, and 3.4 to the $\mathrm{PHY}$ before implementation of the EHAS programme, Table 3. There was an average of 8.3 trips from the HC to the PHY before the implementation of the programme. The average number of nights necessary to stay out for each trip was 2.0 for trips from the HP to the HD and 3.1 for trips to the PHY, Table 4 . The average number of nights for each trip from the HC to the PHY was 2.8.

The 'lost' column in Table 3, as well as in some of the following tables, provides information about the number of health sites that did not report any travel because they did not travel to the HD or the PHY; accordingly, the 'valid' column provides information about the number of health sites reporting that they performed this activity.

After 12 months of use of the telemedicine system, the average number of trips by personnel from a HP to the $\mathrm{HD}$ and from a HC to a PHY was reduced from 4.4 to 2.8 (Table 5), which is equivalent to an average $37 \%$ reduction $(P=0.39)$. The epidemiological reports were sent by email and there were also fewer urgent referrals due to the remote consultation with the reference doctor.

The average unit cost of health-care personnel trips was calculated taking into account transportation costs, per diem allowances and accommodation expenses. Table 6 presents information on the average transportation cost before the implementation of the EHAS programme for trips from HPs and from HCs. The average per diem (subsistence) costs for those trips are presented in Table 7 .

Finally, the cost of overnight accommodation in the trips of the health-care personnel is presented in Table 8.

Table 2 Total monthly variable costs for all 39 telemedicine systems

\begin{tabular}{|c|c|c|}
\hline Resources & Variable cost calculation & Monthly cost (\$) \\
\hline Telephone bill & Five bills of $\$ 50.00+$ one bill of $\$ 25$ & 275.00 \\
\hline Maintenance and repair & $\begin{array}{l}39 \times(1.57 \text { trips by year for each health facilities+per diems of two } \\
\text { days+hostel of one night+spare part of } \$ 100 \text { each three breakdowns) }\end{array}$ & 456.41 \\
\hline Consumables & $39 \times($ paper+distilled water+printer ribbon $)$ & 81.64 \\
\hline Informatics training for new employees & $\begin{array}{l}\text { Two courses of three days each year. Cost of four new pupils by } \\
\text { year not producing for three days ( } \$ 15.40 \text { daily cost by worker)+teacher } \\
\text { cost for six days ( } \$ 37.33 \text { teacher daily cost) }\end{array}$ & 34.06 \\
\hline \multirow[t]{2}{*}{$\begin{array}{l}\text { Personnel developing the distant-learning } \\
\text { courses }\end{array}$} & $\begin{array}{l}\text { (1 doctor }[\$ 800]+1 \text { informatics technician [ } \$ 400] \text { developing the } \\
\text { services)/shared by at least five similar projects }\end{array}$ & 240.00 \\
\hline & Total variable cost of the 39 telemedicine systems & 1087.11 \\
\hline
\end{tabular}

Table 3 Number of trips to the head of the district and to the provincial hospital before the EHAS programme (January 2001) (Answer to the question: How many trips did you do in the last three months?)

\begin{tabular}{|c|c|c|c|c|c|c|}
\hline \multirow{2}{*}{ From } & \multirow{2}{*}{ Destination } & \multicolumn{2}{|c|}{ No } & \multirow{2}{*}{ Mean } & \multirow{2}{*}{ SD } & \multirow{2}{*}{$95 \%$ confidence interval } \\
\hline & & Valid & Lost & & & \\
\hline \multirow[t]{2}{*}{ Health posts } & HD & 25 & 1 & 4.4 & 3.5 & $(3.0-5.8)$ \\
\hline & PHY & 19 & 7 & 3.4 & 3.1 & $(1.9-4.9)$ \\
\hline Health centres & PHY & 6 & 0 & 8.3 & 7.6 & $(0.4-16.2)$ \\
\hline
\end{tabular}

Table 4 Duration of the trips (Answer to the question: How many nights is it necessary to stay out per trip?)

\begin{tabular}{|c|c|c|c|c|c|c|}
\hline \multirow{2}{*}{ From } & \multirow{2}{*}{ Destination } & \multicolumn{2}{|c|}{ No } & \multirow{2}{*}{ Mean } & \multirow{2}{*}{ SD } & \multirow{2}{*}{$95 \%$ confidence interva } \\
\hline & & Valid & Lost & & & \\
\hline \multirow[t]{2}{*}{ Health posts } & HD & 25 & 1 & 2.0 & 1.0 & $(1.6-2.4)$ \\
\hline & PHY & 18 & 8 & 3.1 & 1.6 & $(2.3-3.8)$ \\
\hline Health centres & PHY & 6 & 0 & 2.8 & 2.3 & $(0.4-5.2)$ \\
\hline
\end{tabular}


Table 5 Number of trips after 12 months of effective operation of the EHAS programme (Answer to the question: How many trips did you make in the last 3 months?)

\begin{tabular}{|c|c|c|c|c|c|c|}
\hline \multirow{2}{*}{ From } & \multirow{2}{*}{ Destination } & \multicolumn{2}{|c|}{ No } & \multirow{2}{*}{ Mean $(\$)$} & \multirow{2}{*}{ SD } & \multirow{2}{*}{$95 \%$ confidence interval } \\
\hline & & Valid & Lost & & & \\
\hline \multirow[t]{2}{*}{ Health posts } & HD & 20 & 6 & 2.8 & 1.98 & $(1.9-3.7)$ \\
\hline & PHY & 23 & 3 & 2.9 & 2.37 & $(1.9-3.9)$ \\
\hline Health centres & PHY & 5 & 0 & 5.2 & 2.16 & $(2.5-7.8)$ \\
\hline
\end{tabular}

Table 6 Average transportation cost of the trips (Answer to the question: How much is the cost of the trips (round trip) to the Referral Centre?)

\begin{tabular}{|c|c|c|c|c|c|c|}
\hline \multirow{2}{*}{ From } & \multirow{2}{*}{ Destination } & \multicolumn{2}{|c|}{ No } & \multirow{2}{*}{ Mean (\$) } & \multirow{2}{*}{ SD } & \multirow{2}{*}{$95 \%$ confidence interval } \\
\hline & & Valid & Lost & & & \\
\hline \multirow[t]{2}{*}{ Health posts } & $\mathrm{HD}$ & 24 & $2^{*}$ & 5.4 & 5.1 & $(3.2-7.5)$ \\
\hline & PHY & 18 & 6 & 10.2 & 13.6 & (3.4-16.9) \\
\hline Health centres & PHY & 6 & 0 & 29.8 & 38.3 & $(0-69.6)$ \\
\hline
\end{tabular}

*There were two outliers not used in the study: the HP of Huancayo, $72 \mathrm{~h}$ by river to its referral centre, with a cost of $\$ 225$ for the trip to the HD and of $\$ 234$ to travel to the PHY; and the HP of Vista Alegre, also very long with a cost of $\$ 36$ to go to its HD and $\$ 49$ to go to the PHY

Table 7 Per diem cost for health-care personnel trips (Answer to the question: How much do you spend in subsistence each day you stay in the Referral Centre?)

\begin{tabular}{|c|c|c|c|c|c|c|}
\hline \multirow[b]{2}{*}{ From } & \multirow[b]{2}{*}{ Destination } & \multicolumn{2}{|c|}{ No } & \multirow[b]{2}{*}{ Mean $(\$)$} & \multirow[b]{2}{*}{ SD } & \multirow[b]{2}{*}{$95 \%$ confidence interval } \\
\hline & & Valid & Lost & & & \\
\hline \multirow[t]{2}{*}{ Health posts } & HD & 26 & 0 & 5.4 & 4.7 & $(3.5-7.2)$ \\
\hline & PHY & 20 & 6 & 5.6 & 4.2 & $(3.6-7.5)$ \\
\hline Health centres & PHY & 6 & 0 & 13.5 & 5.5 & $(7.8-19.2)$ \\
\hline
\end{tabular}

Table 8 Cost of accommodation in the trips (Answer to the question: How much is the cost of an overnight stay in the Referral Centre?)

\begin{tabular}{|c|c|c|c|c|c|c|}
\hline \multirow[b]{2}{*}{ From } & \multirow[b]{2}{*}{ Destination } & \multicolumn{2}{|c|}{ No } & \multirow[b]{2}{*}{ Mean $(\$)$} & \multirow[b]{2}{*}{ SD } & \multirow[b]{2}{*}{$95 \%$ confidence interval } \\
\hline & & Valid & Lost & & & \\
\hline \multirow[t]{2}{*}{ Health posts } & $\mathrm{HD}^{*}$ & 26 & 0 & 1.0 & - & - \\
\hline & PHY & 20 & 6 & 2.0 & 1.7 & $(1.2-2.7)$ \\
\hline Health centres & PHY & 6 & 0 & 6.3 & 3.3 & $(2.8-9.6)$ \\
\hline
\end{tabular}

*Non-normal distribution

Table 9 Distribution of the cost of the trips of health care personnel (Answer to the question: Who paid the trip expenses of the health care personnel?)

\begin{tabular}{llll}
\hline & Frequency & Valid \% & 95\% confidence interval \\
\hline Paid with private money* & 29 & 91 & $(75.7-96.6)$ \\
Paid by the municipality & 1 & 3 & $(0.7-15.7)$ \\
Paid half by the Ministry of Health and half by private money & 2 & 6 & $(1.9-20.2)$ \\
Total & 32 & 100 & \\
\hline
\end{tabular}

*The salary of the rural personnel includes the cost of the work trips. So this component cannot be considered as a private cost of the personnel working for the health network

The distribution of the costs of the health-care personnel trips among the agents involved in the health-care process is presented in Table 9.

The average monthly cost for a health-care personnel trip from a HP to the HD was $\$ 23.57$, and the average cost of a trip from a HP to the PHY was $\$ 38.69$. The average monthly cost for a personnel trip from a HC to the PHY was $\$ 82.91$. Thus, there was a monthly cost decrease (saving) for health-care personnel trips after the implementation of the EHAS programme, which was equivalent to $\$ 19.46$ for each HP and to $\$ 86.50$ for each HC. 


\section{Changes in the costs of urgent referrals}

The number of urgent referrals to the hospital before and after the implementation of the EHAS programme are shown in Tables 10 and 11. Prior to the availability of the EHAS project, there was a mean of 11.1 urgent patients referrals per year from HPs, and it was 14.0 from HCs. After implementation of the EHAS programme, the annual number of patient referrals was reduced to 2.5 from HPs $(P=0.03)$ and to 8.4 from HCs $(P=0.17)$.

Table 12 presents the results for the calculation of the average costs of urgent referrals. Table 12 includes only the transportation cost of the trip (fuel, skipper, rent of motor and boat). The overall cost of an urgent referral also includes accommodation and per diem costs of at least a companion, and the hospital bill.

Accommodation costs were calculated assuming a mean stay of four days and three nights (cost of $\$ 40.82$ ), and average observed hospitalization costs amounted to $\$ 100$ for three days.

Table 13 shows the distribution of urgent referral costs among the agents involved in the health-care process.

The monthly cost of urgent referrals decreased after implementation of EHAS by $\$ 114.81$ for HPs and $\$ 100.81$ for HCs.

\section{Net economic effect}

The net economic effect of the EHAS programme was calculated as the magnitude of the net present value of direct cost changes, i.e. the difference between cost before implementation of the EHAS programme and after implementation from the perspective of the whole society in a four-year period. The direct cost changes included were based on: EHAS fixed costs, EHAS variable costs, changes in health-care personnel trip costs, changes in urgent referral costs, changes in traditional training costs, changes in the time of the health-care personnel devoted to travelling to their RC and the time devoted to completing reports, and changes in the time of patients and their relatives (companion) devoted to urgent referrals to the hospital.

The EHAS system can be used to transmit educational material by email, adding an additional benefit in the reduction of the number of traditional health courses for health-care personnel. Monthly savings of 0.33 courses were reported. The average unit cost for a course was calculated including only the cost of the teacher for an average of three days. The transportation

Table 13 Distribution of the costs of urgent referrals (Answer to the question: Who paid for urgent referral costs?)

\begin{tabular}{lccc}
\hline & Frequency & Valid \% & $\begin{array}{l}95 \% \\
\text { confidence } \\
\text { interval }\end{array}$ \\
\hline Ministry of Health & 6 & 19 & $(9-36)$ \\
Patient & 14 & 44 & $(28-61)$ \\
Municipality & 10 & 31 & $(18-49)$ \\
Half Ministry of Health & 2 & 6 & $(2-20)$ \\
$\quad$ and Half Municipality & & & \\
Total & 32 & & \\
\hline
\end{tabular}

Table 10 Number of urgent moves before the EHAS programme (January 2001) (Answer to the question: How many patients' urgent referrals did you have in the last year?)

\begin{tabular}{|c|c|c|c|c|c|c|}
\hline \multirow{2}{*}{ From } & \multirow{2}{*}{ Destination } & \multicolumn{2}{|c|}{ No } & \multirow{2}{*}{ Mean } & \multirow{2}{*}{ SD } & \multirow{2}{*}{$95 \%$ confidence interva } \\
\hline & & Valid & Lost & & & \\
\hline Health posts & HD & 26 & 0 & 11.1 & 13.3 & $(5.4-16.2)$ \\
\hline Health centres & PHY & 6 & 0 & 14.0 & 8.2 & $(5.4-22.2)$ \\
\hline
\end{tabular}

Table 11 Urgent moves after 12 months of effective operation of the EHAS programme (Answer to the question: How many urgent referrals did you have in the last year?)

\begin{tabular}{|c|c|c|c|c|c|c|}
\hline \multirow[b]{2}{*}{ From } & \multirow[b]{2}{*}{ Destination } & \multicolumn{2}{|c|}{ No } & \multirow[b]{2}{*}{ Mean } & \multirow[b]{2}{*}{ SD } & \multirow[b]{2}{*}{$95 \%$ confidence interval } \\
\hline & & Valid & Lost & & & \\
\hline Health posts & HD & 24 & 1 & 2.5 & 2.1 & $(1.6-3.3)$ \\
\hline Health centres & PHY & 6 & 0 & 8.4 & 4.9 & $(2.3-14.4)$ \\
\hline
\end{tabular}

Table 12 Average transportation cost per urgent referral (Answer to the question: How much is the cost of an urgent patient referral?)

\begin{tabular}{|c|c|c|c|c|c|c|}
\hline \multirow{2}{*}{ From } & \multirow{2}{*}{ Destination } & \multicolumn{2}{|c|}{ No } & \multirow{2}{*}{ Mean $(\$)$} & \multirow{2}{*}{ SD } & \multirow{2}{*}{$95 \%$ confidence interval } \\
\hline & & Valid & Lost & & & \\
\hline Health posts & $\mathrm{HD}$ & 26 & 0 & 32.1 & 26.6 & $(21.3-42.7)$ \\
\hline Health centres & PHY & 6 & 0 & 87.5 & 53.9 & $(30.9-144)$ \\
\hline
\end{tabular}


costs, per diems and accommodation are included in the general data of Tables 4 and 5 .

The EHAS programme resulted in a reduction in the time of the health-care personnel devoted to travelling to their $\mathrm{RC}$ and the time devoted to completing reports. The monetary value of the saved time of health-care personnel was calculated using the average reduction in the number of trips to the $\mathrm{RC}$, the average duration of each trip, and the daily cost for a technician (\$12.50) and for a doctor (\$40.62). Also, the monetary value of the savings accrued in the time devoted to completing reports was calculated using the average number of hours saved by establishment $(7.2 \mathrm{~h}$ per month) and the average daily cost of personnel.

The reduction in the number of urgent referrals after programme implementation also implied a decrease in the time devoted by the patient and a companion of the patient to the process of receiving health care. The monetary value of this reduction in the time of the patient and his/her companion was calculated taking into account the average reduction in urgent referrals, one person accompanying each patient for four days and the average daily salary $(\$ 12.50)$.

The present value of the net economic effect of the EHAS programme during four years is shown in Table 14 for each category using both 3 and 5\% discount rates. The overall net economic effect of the EHAS programme over a four-year period was clearly positive, amounting to $\$ 320,126$ (5\% discount rate) in net savings, and indicating that the EHAS programme resulted in an important reduction in overall costs from the perspective of society. Therefore, one may conclude that the telemedicine programme is efficient and increases societal welfare. Direct health-care cost savings accounted for $64 \%$ of the overall savings, and productivity gains accounted for $36 \%$. The ratio of overall avoided costs (savings) to additional costs is nearly 2.5 times (2.4 times with a 5\% discounting rate).

Table 14 Net economic effect of the EHAS programme (costs in US\$ in 2002)

\begin{tabular}{lcc}
\hline $\begin{array}{l}\text { Changes in resource } \\
\text { consumption }\end{array}$ & $\begin{array}{l}\text { Present value } \\
\text { (3\% discount rate) }\end{array}$ & $\begin{array}{l}\text { Present value } \\
\text { (5\% discount rate) }\end{array}$ \\
\hline EHAS fixed costs & $-196,326$ & $-196,326$ \\
EHAS variable costs & $-49,946$ & $-37,303$ \\
Personnel trip savings & 56,433 & 54,880 \\
Urgent referral savings & 201,209 & 195,672 \\
Training cost savings & 66,218 & 64,396 \\
Savings of personnel time & 125,439 & 121,987 \\
Direct health-care cost & 203,027 & 203,306 \\
& & 116,821 \\
Productivity gains of patients & 120,127 & 116,821 \\
Direct non-health-care cost & 120,127 & 320,126 \\
& & \\
Overall net cost & 323,154 & \\
\hline
\end{tabular}

${ }^{*}$ Negative figures indicate costs, and positive figures indicate savings
Cost savings that accrued from the reduction in direct health-care costs through fewer personnel trips and from a reduction in the number of urgent referrals more than outweighed the additional fixed capital and variable costs of the telemedicine equipment. In fact, the EHAS programme resulted in overall net savings after the second year of operation.

The main results obtained in this paper were maintained after performing a one-way sensitivity analysis using two values for the discount rates (3 and 5\%; Table 14), and using the lower and upper values of the confidence interval for the number of urgent referrals to the hospital from each health establishment. The number of urgent referrals was selected for sensitivity analysis because its net cost impact in this cost analysis is the most important one among the different categories of resources considered. In the sensitivity analysis, a pessimistic scenario was defined using the lower limit of the confidence interval for the number of referrals observed before the implementation of the programme, and the higher limit after the implementation and a 5\% discount rate. Only in this extreme case, would net savings from changes in the number of urgent referrals disappear. However, even in this case, the overall result of the programme continues to offer net savings $(\$ 29,658)$.

\section{Discussion}

It is important to note that simply considering direct cost-savings from the reduction in the number of personnel trips and urgent referrals, and from direct variable costs of the EHAS telemedicine system, showed that savings of $\$ 115.90$ per month were obtained in each establishment affected by the project. Second, from the perspective of society, the EHAS telemedicine system was efficient. That is, cost-savings more than outweighed additional fixed and variable costs in a four-year period. This conclusion was robust to changes in the discounting rate adopted in the evaluation and also to changes in the number of urgent patient referrals.

From the budgetary perspective of the health network, it is necessary to consider that the personnel trips for coordination of activities, training, delivery of reports and drug distribution are assumed directly by the workers in the countryside. Therefore, the calculated savings cannot be attributed to the healthcare network. Nevertheless, considering that the health-care network directly bears the cost of $22 \%$ of trip expenses and hospitalization (Table 13), the EHAS programme allows for budgetary savings of $\$ 794$ per 
month. Therefore, if we compare the monthly variable costs of the telemedicine system that are directly paid by the health-care network ( $\$ 731$; maintenance and repair, and telephone), with those savings, we can conclude that the Alto Amazonas provincial health network has a positive balance of $\$ 63$ for each month of system operation. This confirms that the additional running costs (telephone and maintenance) introduced by the telemedicine system are lower than the direct cost-savings it produces for the health-care network.

The cost analysis performed in the present study may have some limitations. First, there may be inaccuracies arising from the use of people in charge of health facilities themselves as a source of information. However, this was the only possible source of information. Second, the simple before-after comparison design employed in this cost analysis can only provide insight into general trends - it is not a randomized controlled trial. Nonetheless, no other coincidental interventions were identified during the study period in the area where the EHAS project was developed. Third, it is difficult to separate the economic effect of the voice communications and the data communications. We suspect that the urgent referral saving was related to the voice communication, and the personnel trip savings to the data communication, but this could not be confirmed in the present study.

Although rural areas of developing countries differ in many aspects and problems, and the different health systems do not work in the same way, the EHAS project demonstrates that telemedicine may represent an efficient intervention for rural health in developing countries. As observed in the present cost analysis, in order to be efficient, telemedicine services in this environment do not require expensive, high bandwidth communications. This is promising for the improvement of health care in rural areas of developing countries.

Acknowledgements: We thank the people who work for the EHAS programme from the partner institutions: NGO Engineering without Borders and Polytechnic University of Madrid from Spain, Catholic and Cayetano Universities from Peru. We are also grateful for the cooperation of many workers and managers of the Peruvian Ministry of Health in Lima and Alto Amazonas, as well as their colleagues in the Peruvian Ministry of Communication and institutions that support the activities of the programme: CICYT, AECI, CYTED, UPM, OSIPTEL.

\section{References}

1 Martinez A, Villarroel V, Seoane J, del Pozo F. Analysis of information and communication needs in rural primary health care in developing countries. IEEE Trans Inf Technol Biomed 2005;9:66-72

2 Martinez A, Villarroel V, Seoane J, del Pozo F. Rural telemedicine for primary healthcare in developing countries. IEEE Technol Soc Mag 2004;23:13-22

3 Martinez A, Lopez DM, Saez A, et al. Improving epidemiologic surveillance and health promoter training in Rural Latin America through ICT. Telemed J E-Health 2005;11:468-76

4 Martinez A, Villarroel V, Seoane J, del Pozo F. A study of a rural telemedicine system in the Amazon region of Peru. J Telemed Telecare 2004;10:219-25 